\title{
Lithium isotope fractionation in aqueous glass dissolution
}

\author{
T. L. GOÛT ${ }^{1 *}$, S. MISRA ${ }^{1,2}$, E. T. TIPPER ${ }^{1}$,
} M. S. BOHLIN ${ }^{1,3}$, R. GUO ${ }^{1,4}$, I. FARNAN ${ }^{1}$

${ }^{1}$ Department of Earth Sciences, University of Cambridge, Downing Street, Cambridge, CB2 3EQ, UK.

(*correspondence: tlg29@cam.ac.uk)

${ }^{2}$ Centre for Earth Sciences, Indian Institute of Science, Bangalore 560012, India

${ }^{3}$ Department of Earth Sciences, Uppsala University, Villavägen 16, 75236 Uppsala, Sweden

${ }^{4}$ Department of Earth System Science, Tsinghua University, Beijing, China

High-level nuclear waste formed during reprocessing activities is commonly vitrifed into a borosilicate glass for permanent disposal within a geological disposal facility. However, aqueous corrosion of these glassy wasteforms by groundwater presents a key mechanism for radionuclide release over geological timescales. Consequently, the quantification of radionuclide release and safe geological disposal of these waste products demands that their dissolution mechanisms are thoroughly understood and modelled.

Here, lithium isotope fingerprinting techniques were applied to glass leachates to directly trace the mechanisms by which lithium was leached from the glass and the role of diffusion throughout aqueous glass dissolution. Experiments took place through leaching a simplified seven-component analogue of a complex Magnox waste glass in deionised water at $90{ }^{\circ} \mathrm{C}$ for up to 98 days. Additionally, a refreshed leachant experiment was used to further probe the role of the altered glass layers as passivating, diffusive barriers to dissolution at long leaching durations. Isotope specific nuclear magnetic resonance was applied to leached glass powders to probe the extent to which lithium was incorporated into secondary phases during dissolution.

The initial absence of lithium isotope fractionation in the leachates supported congruent models of glass dissolution during the earlier dissolution regimes. However, isotopic fractionation during the later dissolution regimes was consistent with lithium leaching through diffusive processes. Further, lithium was shown to be incorporated into secondary phases continually throughout the later stages of dissolution.

The isotopic techniques employed here provide a crucial additional dimension with which to understand the dissolution mechanisms of glasses beyond the conventional leachate concentration measurements and nano-scale postprocess analyses of altered glass cross sections. 